\title{
Do sex and site matter? Different age distribution in melanoma of the trunk among Swedish men and women
}

\author{
B. Pérez-Gómez, N. Aragonés, P. Gustavsson, * V. Lope, G. López-Abente and M. Pollán \\ Environmental and Cancer Epidemiology Unit, National Centre for Epidemiology, Carlos III Institute of Health, 28029 Madrid, Spain and CIBER en \\ Epidemiologia, 4 Salud Publica (CIBERESP), Spain \\ *Division of Occupational Health, Department of Public Health Sciences, Karolinska Institutet, Stockholm, Sweden
}

\section{Summary}

\section{Correspondence \\ Beatriz Pérez-Gómez. \\ E-mail: bperez@isciii.es}

Accepted for publication

9 November 2007

Key words

body regions, cohort study, epidemiology,

melanoma, sex, Sweden

Conflicts of interest

None declared.
Background Recent research on cutaneous malignant melanoma (CMM) points to the coexistence of several biological pathways linked to the anatomical site of the lesion, which could lead to this neoplasm. Although the different anatomical distribution of CMM by sex is usually attributed to gender-specific patterns of sun exposure, it has been suggested that an alternative explanation might lie in gender-specific site susceptibility.

Objectives This paper aimed at analysing the age distribution of CMM by site and sex to gain in-depth knowledge of differences between the sexes.

Methods Using a large Swedish cohort comprising 2992166 workers, Poisson models were fitted to estimate age-specific incidence rates by site and sex, duly adjusted for several factors that might account for changes in environmental exposures (period, birth cohort, socioeconomic level, latitude and rurality).

Results Incidence rates were $17 \cdot 4$ cases per 100000 person-years in men and 16.5 in women. Sex differences were particularly striking for CMM of the trunk, where both crude and adjusted incidence rates displayed a steady increase with age in men, but reached a plateau in women at around four cases per 100000 person-years from the 40-45-year age group (perimenopausal period) upwards. There was an almost fivefold increase in the sex ratio for this body site between the younger and older age groups, a difference which could not be attributed to period or cohort effects.

Conclusions If different aetiological pathways can be assumed to lead to melanoma, then disparities between men and women, particularly in CMM of the trunk, suggest that a possible interaction between site and sex should be borne in mind.
Cutaneous malignant melanoma $(\mathrm{CMM})$ is the most aggressive form of common skin cancer. To date, epidemiological research has succeeded in furnishing relevant information on its aetiology, with familial cases accounting for $4-15 \% .^{1}$ Likewise, some cutaneous and pigmentary traits that are associated with sunburn protection and have recently been linked to certain melanocortin-1 receptor polymorphisms ${ }^{2}$ increase the risk of developing this neoplasm. Among environmental exposures, ultraviolet (UV) radiation is the only established aetiological agent, with sun exposure thought to be responsible for almost $65 \%$ of cases. ${ }^{3}$ In Sweden at least, melanoma incidence displays a north-south gradient, ${ }^{4,5}$ probably related to differences in sunlight intensity associated with latitude. ${ }^{6}$ The disease is also more frequent among affluent socioeconomic classes $^{7}$ and in urban settings, ${ }^{6}$ a finding that has been linked to travel habits to sunny countries. Other lifestyle-related and environmental exposures, such as occupation, ${ }^{5,8}$ tobacco, drug or alcohol use, ${ }^{9}$ diet and tea/coffee drinking, ${ }^{10}$ and contraceptive use, ${ }^{11}$ have been studied as possible modifiers of melanoma risk, albeit with inconclusive results.

One of the specific features in melanoma epidemiology is the different anatomical distribution of lesions in men and women, which has usually been attributed to gender-specific patterns of sun exposure. ${ }^{12}$ If body surface area is taken into account, the highest rates are normally found on fully exposed sites, such as the ears, in both sexes. ${ }^{12,13}$ In absolute numbers, however, the trunk is the most common site in men and legs are the primary site in women, and these differences are found in countries with widely varying latitude. ${ }^{14}$ An alternative explanation could lie in site-dependent susceptibility of melanocytes, ${ }^{15}$ as identical sex differences in naevus density on the back and lower limbs of young children, which could 
not be explained by differences in personal sun exposure, have recently been described in countries such as Australia ${ }^{16}$ and Canada, ${ }^{17}$ and in Central and Southern Europe. ${ }^{18}$ According to Autier et al., ${ }^{18}$ this could imply that sex-related differences in sun-exposure behaviours, dressing or clothing would merely add their effects to an inherited sex-dependent propensity to develop naevi - or melanoma - at any given body site. The relatively new insight provided by molecular epidemiology has added interesting data to the overall picture. Several authors have suggested the coexistence of different site-related biological pathways leading to melanoma, ${ }^{19}$ which could explain why the relevance of some known risk factors differs by anatomical location. ${ }^{20-23}$

As in all other neoplasms, another fundamental risk factor in melanoma epidemiology is age. However, explanations of changes in age-related risk are not straightforward, as they may reflect biological changes due to the ageing process as well as cumulative and/or temporal changes in environmental exposures. In this respect, differences in age-related risk between the sexes could be due to sex-specific age-related body changes, or to variable gender-specific patterns of exposure. To date, several papers have included a breakdown of age-related rates by sex within their descriptive analysis of melanoma, ${ }^{13,24,25}$ yet none has specifically focused on the differences between them or considered additional known confounding factors linked to sun exposure.

This paper aimed at analysing the age distribution of CMM by site and sex to gain in-depth knowledge of differences between the sexes. For this purpose, we took advantage of a large Swedish occupational retrospective cohort ${ }^{26}$ to estimate age-specific incidence rates adjusted for several factors that might indirectly account for some environmental exposures (i.e. temporal variations in sun-exposure patterns associated with birth cohort or period of diagnosis, socioeconomic level and rurality, as proxies of intermittent UV exposures due to sunbathing on holiday trips or due to latitude, which reflects constant UV residential radiation).

\section{Materials and methods}

The base population for this retrospective cohort was made up of all Swedish men and women who reported being gainfully employed at the time of the 1970 census, present in the 1960 census, and still alive and aged 25-64 years on 1 January 1971. The cohort included 1890497 men and 1101669 women followed up until the end of 1989.

Information was drawn from two linked data sets, namely: (i) the Swedish Cancer Environment Register, with information on incident cases (from the Swedish Cancer Registry, founded in 1958, which covers the entire population of Sweden; overall reporting to this registry, compulsory for all health providers, is estimated to be $96 \%$ of all diagnosed cases), including a number of demographic variables from the 1960 and 1970 censuses, which were used to compute specific rate numerators; and (ii) a background population register, comprising all individuals in both the
1970 and 1960 censuses, with information on occupation and residence in 1970 and, where applicable, date of death. This register was used to calculate specific rate denominators. Immigrants have been estimated to represent less than $1 \%$ of this cohort because in Sweden immigration occurred mainly after $1960 .{ }^{27}$ A detailed description of the record linkage between these two registers will be found elsewhere. $^{28}$

Melanoma was coded under rubric 190 of the International Classification of Diseases (7th revision). The fourth digit specifies body site. In situ melanomas are included. All head and neck melanomas were analysed jointly. CMMs with multiple or unspecified sites represented $0 \cdot 7 \%$ and $10 \cdot 6 \%$ of all registered melanomas in men, and $0.4 \%$ and $9 \cdot 8 \%$ in women. These cases were not included in the site-specific analysis.

Occupation was classified according to the Nordic Classification of Occupations. Each occupation is represented by a three-digit number. The first digit refers to one of 10 major occupational sectors (0-9), where higher numbers indicate manual occupations and lower numbers nonmanual occupations, often requiring longer education and associated with a higher socioeconomic status. Person-years were accumulated from 1971 until date of death or up to year-end 1989. The overall person-time that each person contributed to the study was allocated to the corresponding cells of the variables of stratification, namely: sex; occupational sector - used as a surrogate of socioeconomic level; county and size of town of residence in 1970 (under 2000, 2000-20 000, 20 000-100 000 and > 100000 inhabitants); 5-year age-group; and the calendar period (1971-75, 1976-80, 1981-85 and 1986-89). Age and period were time-dependent variables. The exact number of person-years was computed.

Swedish counties were classified into low, medium or high risk for melanoma using a Poisson model adjusted for sex, age, period, occupational sector and town size, and taking the cohort's overall incidence as reference. This classification was also geographically meaningful, with low risks in the north, and all the high risks in Sweden's southern counties. ${ }^{5}$

Initially, we calculated crude age-specific and age-adjusted rates for each anatomical site by sex, taking the European standard population as reference, as well as sex incidence rate ratios.

In a second step, multivariate age-period-cohort log-linear Poisson models were fitted, including geographical area, occupational sector and town size as additional confounding factors, in order to estimate the adjusted age-specific incidence rates. Separate models were constructed for each site and sex. The linear relationship linking age, period and cohort means that any model which includes all three factors simultaneously may have infinite solutions (nonidentifiability problem). ${ }^{29}$ There have been multiple methodological approaches to this problem: one of the most common is the solution proposed by De Carli and La Vecchia, ${ }^{30}$ which was used in this case. However, our study was based on a fixed cohort, in that all the members entered at a specific point in time. Consequently 
only those age groups that were present throughout the entire study, namely from 40 to 65 years, could be used in this last analysis.

\section{Results}

Across follow-up, 6187 cases of CMM were observed among men, with trunk accounting for 51\%, head/neck and upper limbs for $12 \%$ each, and lower limbs for an additional $11 \%$. Among women, 3598 cases of CMM were diagnosed, with lower limbs being the most frequent location (38\%), followed by trunk (23\%), upper limbs (18\%) and, finally, head/neck (11\%).

For all melanoma cases, incidence rates in the cohort were $17 \cdot 4$ cases per 100000 person-years among men and 16.5 per 100000 person-years among women, and the sex incidence rate ratio was $1 \cdot 05$. Table 1 shows crude age-specific and age-adjusted incidence rates by body site and sex, along with sex ratios by site. Head and neck risks displayed an exponential increase with age in both sexes, and an analogous, although less marked, trend could be seen for the upper limbs. The most striking point, however, was the difference between men and women in CMM of the trunk: both registered similar rates until age $40-45$ years but the trends proved completely different thereafter. While incidence rates in men aged over 40 years registered an increase of 15\% [95\% confidence interval (CI) 13-17] with each age group, in women they remained stable as from age 40 years $(-0.04 \% ; 95 \% \mathrm{CI}$ -0.08 to 0.00 ). While there was an almost fivefold increase in the sex ratio for this body site between the younger and older age groups, only small variations with age were observed for other sites. Lastly, rates for the lower limbs increased until ages 45-49 years and levelled off thereafter in both sexes, although among men incidence rates registered a further rise in the oldest age groups.

Figure 1 depicts the age-specific rates by site and sex obtained from age-cohort-period Poisson models, which were also adjusted for town size, geographical distribution and socioeconomic level, as indirect estimators of environmental sun exposure. Again, clear differences between the two sexes were seen in respect of the trunk: whereas there were small changes in risk with age among women in contrast to a steady rise among men, this possible interaction was not in evidence for the other sites.

\section{Discussion}

The size of our cohort, and the large number of cases registered due to the high CMM incidence in Sweden, ${ }^{31}$ rendered it possible to study differences in age incidence patterns between sexes and among sites simultaneously. Our results confirm a different site distribution of CMM by sex and show that in melanoma of the trunk, age distribution clearly differs between men and women. These differences, which are attributable neither to cohort or period effects nor, probably, to sun-exposure patterns, suggest that gender might - for this site, at least - be playing the role of a modifying factor and should therefore be taken into account.

As sun exposure and personal susceptibility are the main risk factors for melanoma, the lack of direct personal data on these might be seen as a relevant limitation in our study. However, genetic susceptibility or skin characteristics would hardly account for the sex differences observed in trunk melanomas. The homogeneity of the population and the relatively low immigration rate across the study period reduce possible confounding due to racial patterns. With regard to individual sun exposure, regular or intermittent, our data furnish indirect information that might enable this to be taken into account. Firstly, given the relationship between latitude and UV radiation, ${ }^{6}$ regular exposure to sunlight would be partly reflected by the geographical location of each subject's town of residence. Secondly, holiday travel to sunny countries, a factor known to be the main source of intermittent sun exposure among Swedish subjects, can at least be partly considered, as town size has been shown to be a good surrogate for frequency of foreign travel, estimated on the basis of passport use. ${ }^{4}$ Moreover, the occupational nature of our cohort allowed us to include occupational sector in our models as a surrogate for socioeconomic level. In this connection, a significant correlation between high travelling frequency and high educational level ${ }^{6}$ or higher social class ${ }^{7}$ has also been reported. However, the exclusion of the unemployed population may perhaps entail a certain selection bias, particularly in women, as working women might differ from home-makers in many lifestyle-related factors. ${ }^{32}$

In general, differences in anatomical distribution between men and women have been considered a result of clothing patterns. Distribution of naevi in young children does not support this clothing-related explanation, however, as the same sex differences in naevus density on the back and lower limbs of young children, which could not be explained by their differences in personal sun exposure, have been reported. ${ }^{16,18}$ There are additional inconsistent points in this theory: although the higher proportion of cases in legs in women might be partially explained by the low sun protection afforded by women's stockings, ${ }^{33}$ the remarkable predominance of the trunk among other sites in men is not so easily explained. Recreational male activities that normally bare the trunk also imply the use of shorts or swimming trunks, thus exposing the legs to the sun's rays. Moreover, Chen et al. ${ }^{34}$ also found that neither site-specific sunburns nor water-activity clothing habits could explain sex differences in melanoma risk among sites. Besides, sun exposure of the trunk does not vary that much between men and women: on the beach, female onepiece swimsuits partially hide the trunk, but women frequently wear bikinis or even go topless, and summer female casual clothes often leave part of the back and front of the trunk exposed to the sun.

Another possible explanation could be a more frequent use of sunscreen, sunblock and sun creams among women, but the possible preventive effect of these products for this neoplasm remains unclear. ${ }^{35}$ Thus, if site-specific sun exposure 
Table 1 Age-specific and age-adjusted incidence rates of melanoma by sex and anatomical location in a Swedish occupational cohort. Cases per 100000 person-years

\begin{tabular}{|c|c|c|c|c|c|c|c|}
\hline \multirow{2}{*}{$\begin{array}{l}\text { Age cohort } \\
\text { (years) }\end{array}$} & \multicolumn{3}{|l|}{ Men } & \multicolumn{3}{|c|}{ Women } & \multirow{2}{*}{$\begin{array}{l}\text { Sex } \\
\text { ratic }\end{array}$} \\
\hline & Cases & Rate & $95 \% \mathrm{CI}$ & Cases & Rate & $95 \% \mathrm{CI}$ & \\
\hline \multicolumn{8}{|l|}{ Head and neck } \\
\hline \multicolumn{8}{|l|}{ Age-specific rates } \\
\hline $25-29$ & 6 & $0 \cdot 49$ & $0 \cdot 18-1 \cdot 07$ & 4 & $0 \cdot 48$ & $0 \cdot 13-1 \cdot 23$ & $1 \cdot 03$ \\
\hline $30-34$ & 11 & $0 \cdot 47$ & $0.23-0.83$ & 10 & $0 \cdot 68$ & $0 \cdot 32-1 \cdot 24$ & 0.69 \\
\hline $35-39$ & 29 & $0 \cdot 86$ & $0 \cdot 58-1 \cdot 24$ & 14 & $0 \cdot 68$ & $0 \cdot 37-1 \cdot 14$ & $1 \cdot 27$ \\
\hline $40-44$ & 40 & $0 \cdot 96$ & $0 \cdot 69-1 \cdot 31$ & 17 & $0 \cdot 67$ & $0.39-1.07$ & $1 \cdot 45$ \\
\hline $45-49$ & 51 & $1 \cdot 28$ & $0.95-1.68$ & 29 & $1 \cdot 16$ & $0 \cdot 78-1 \cdot 67$ & $1 \cdot 10$ \\
\hline $50-54$ & 64 & $1 \cdot 58$ & $1 \cdot 22-2 \cdot 02$ & 36 & $1 \cdot 35$ & $0.95-1.88$ & $1 \cdot 17$ \\
\hline $55-59$ & 101 & $2 \cdot 47$ & $2 \cdot 01-3 \cdot 00$ & 43 & $1 \cdot 59$ & $1 \cdot 15-2 \cdot 15$ & 1.55 \\
\hline $60-64$ & 120 & $3 \cdot 05$ & $2 \cdot 53-3 \cdot 64$ & 66 & $2 \cdot 67$ & $2 \cdot 06-3 \cdot 40$ & $1 \cdot 14$ \\
\hline $65-69$ & 140 & $4 \cdot 32$ & $3 \cdot 64-5 \cdot 10$ & 83 & $4 \cdot 39$ & $3 \cdot 50-5 \cdot 45$ & 0.98 \\
\hline $70-74$ & 111 & $5 \cdot 80$ & $4 \cdot 77-6 \cdot 99$ & 57 & $5 \cdot 20$ & $3 \cdot 94-6 \cdot 73$ & $1 \cdot 12$ \\
\hline$\geq 75$ & 108 & $10 \cdot 25$ & $8 \cdot 41-12 \cdot 38$ & 40 & $6 \cdot 85$ & $4 \cdot 89-9 \cdot 32$ & $1 \cdot 50$ \\
\hline Age-adjusted rate & 781 & $2 \cdot 38$ & $2 \cdot 379-2 \cdot 381$ & 399 & $1 \cdot 90$ & $1 \cdot 899-1.901$ & $1 \cdot 25$ \\
\hline \multicolumn{8}{|l|}{ Trunk } \\
\hline \multicolumn{8}{|l|}{ Age-specific rates } \\
\hline $25-29$ & 20 & $1 \cdot 65$ & $1 \cdot 01-2 \cdot 54$ & 16 & 1.92 & $1 \cdot 10-3 \cdot 12$ & 0.86 \\
\hline $30-34$ & 59 & $2 \cdot 50$ & $1 \cdot 90-3 \cdot 22$ & 40 & $2 \cdot 71$ & $1.93-3.69$ & 0.92 \\
\hline $35-39$ & 136 & $4 \cdot 05$ & $3 \cdot 40-4 \cdot 79$ & 60 & $2 \cdot 92$ & $2 \cdot 23-3 \cdot 75$ & $1 \cdot 39$ \\
\hline $40-44$ & 239 & $5 \cdot 76$ & $5 \cdot 06-6 \cdot 54$ & 115 & $4 \cdot 51$ & $3 \cdot 72-5 \cdot 41$ & $1 \cdot 28$ \\
\hline $45-49$ & 337 & $8 \cdot 46$ & $7 \cdot 58-9 \cdot 41$ & 120 & $4 \cdot 82$ & $3 \cdot 99-5 \cdot 76$ & $1 \cdot 76$ \\
\hline $50-54$ & 417 & $10 \cdot 29$ & $9 \cdot 32-11 \cdot 33$ & 123 & $4 \cdot 63$ & $3 \cdot 85-5 \cdot 52$ & $2 \cdot 22$ \\
\hline $55-59$ & 486 & $11 \cdot 88$ & $10 \cdot 84-12 \cdot 98$ & 114 & $4 \cdot 22$ & $3 \cdot 48-5 \cdot 07$ & $2 \cdot 81$ \\
\hline $60-64$ & 517 & $13 \cdot 12$ & $12 \cdot 01-14 \cdot 30$ & 114 & $4 \cdot 61$ & $3 \cdot 80-5 \cdot 54$ & $2 \cdot 85$ \\
\hline $65-69$ & 480 & $14 \cdot 83$ & $13 \cdot 53-16 \cdot 21$ & 68 & $3 \cdot 60$ & $2 \cdot 80-4 \cdot 56$ & $4 \cdot 12$ \\
\hline $70-74$ & 296 & $15 \cdot 47$ & $13 \cdot 76-17 \cdot 33$ & 38 & $3 \cdot 47$ & $2 \cdot 45-4 \cdot 76$ & $4 \cdot 46$ \\
\hline$\geq 75$ & 177 & $16 \cdot 81$ & $14 \cdot 42-19 \cdot 47$ & 24 & $4 \cdot 11$ & $2 \cdot 63-6 \cdot 11$ & 4.09 \\
\hline Age-adjusted rate & 3164 & $8 \cdot 39$ & $8 \cdot 387-8 \cdot 393$ & 832 & $3 \cdot 72$ & $3 \cdot 718-3 \cdot 721$ & $2 \cdot 26$ \\
\hline \multicolumn{8}{|l|}{ Upper limbs } \\
\hline \multicolumn{8}{|l|}{ Age-specific rates } \\
\hline $25-29$ & 4 & $0 \cdot 33$ & $0 \cdot 09-0 \cdot 84$ & 5 & $0 \cdot 60$ & $0 \cdot 19-1 \cdot 40$ & 0.55 \\
\hline $30-34$ & 15 & 0.63 & $0 \cdot 36-1 \cdot 05$ & 17 & $1 \cdot 15$ & $0.67-1.84$ & 0.55 \\
\hline $35-39$ & 35 & $1 \cdot 04$ & $0 \cdot 73-1 \cdot 45$ & 40 & $1 \cdot 94$ & $1 \cdot 39-2 \cdot 65$ & 0.54 \\
\hline $40-44$ & 65 & 1.57 & $1 \cdot 21-2 \cdot 00$ & 80 & $3 \cdot 13$ & $2 \cdot 49-3 \cdot 90$ & 0.50 \\
\hline $45-49$ & 79 & $1 \cdot 98$ & $1 \cdot 57-2 \cdot 47$ & 67 & $2 \cdot 69$ & $2 \cdot 08-3 \cdot 42$ & 0.74 \\
\hline $50-54$ & 92 & $2 \cdot 27$ & $1 \cdot 83-2 \cdot 78$ & 74 & $2 \cdot 79$ & $2 \cdot 19-3 \cdot 50$ & 0.81 \\
\hline $55-59$ & 95 & $2 \cdot 32$ & $1 \cdot 88-2 \cdot 84$ & 83 & $3 \cdot 08$ & $2 \cdot 45-3 \cdot 81$ & 0.75 \\
\hline $60-64$ & 121 & $3 \cdot 07$ & $2.55-3.67$ & 96 & $3 \cdot 88$ & $3 \cdot 15-4 \cdot 74$ & 0.79 \\
\hline $65-69$ & 128 & $3 \cdot 95$ & $3 \cdot 30-4 \cdot 70$ & 85 & $4 \cdot 50$ & $3 \cdot 59-5 \cdot 56$ & 0.88 \\
\hline $70-74$ & 93 & $4 \cdot 86$ & $3 \cdot 92-5 \cdot 95$ & 64 & $5 \cdot 84$ & $4 \cdot 49-7 \cdot 45$ & 0.83 \\
\hline$\geq 75$ & 50 & $4 \cdot 75$ & $3 \cdot 52-6 \cdot 26$ & 37 & $6 \cdot 33$ & $4 \cdot 46-8 \cdot 73$ & 0.75 \\
\hline Age-adjusted rate & 777 & $2 \cdot 10$ & $2 \cdot 099-2 \cdot 101$ & 648 & $2 \cdot 83$ & $2 \cdot 829-2 \cdot 831$ & 0.74 \\
\hline \multicolumn{8}{|l|}{ Lower limbs } \\
\hline \multicolumn{8}{|l|}{ Age-specific rates } \\
\hline $25-29$ & 5 & $0 \cdot 41$ & $0 \cdot 13-0.96$ & 13 & 1.56 & $0 \cdot 83-2 \cdot 67$ & $0 \cdot 26$ \\
\hline $30-34$ & 25 & $1 \cdot 06$ & $0.68-1.56$ & 58 & 3.93 & $2 \cdot 98-5 \cdot 07$ & $0 \cdot 27$ \\
\hline $35-39$ & 46 & $1 \cdot 37$ & $1 \cdot 00-1 \cdot 83$ & 100 & $4 \cdot 86$ & $3 \cdot 96-5 \cdot 91$ & $0 \cdot 28$ \\
\hline $40-44$ & 64 & $1 \cdot 54$ & $1 \cdot 19-1.97$ & 156 & $6 \cdot 11$ & $5 \cdot 19-7 \cdot 15$ & $0 \cdot 25$ \\
\hline $45-49$ & 102 & $2 \cdot 56$ & $2 \cdot 09-3 \cdot 11$ & 185 & $7 \cdot 43$ & $6 \cdot 40-8 \cdot 58$ & $0 \cdot 34$ \\
\hline $50-54$ & 68 & $1 \cdot 68$ & $1 \cdot 30-2 \cdot 13$ & 179 & $6 \cdot 74$ & $5 \cdot 79-7 \cdot 80$ & $0 \cdot 25$ \\
\hline $55-59$ & 91 & $2 \cdot 22$ & $1 \cdot 79-2 \cdot 73$ & 194 & $7 \cdot 19$ & $6 \cdot 21-8 \cdot 27$ & $0 \cdot 31$ \\
\hline $60-64$ & 84 & $2 \cdot 13$ & $1 \cdot 70-2 \cdot 64$ & 183 & $7 \cdot 40$ & $6 \cdot 37-8 \cdot 56$ & $0 \cdot 29$ \\
\hline $65-59$ & 96 & $2 \cdot 97$ & $2 \cdot 40-3 \cdot 62$ & 153 & $8 \cdot 10$ & $6 \cdot 87-9 \cdot 49$ & 0.37 \\
\hline $70-74$ & 75 & $3 \cdot 92$ & $3 \cdot 08-4.91$ & 83 & $7 \cdot 57$ & $6 \cdot 03-9 \cdot 38$ & 0.52 \\
\hline$\geq 75$ & 42 & $3 \cdot 99$ & $3 \cdot 52-6.60$ & 49 & $8 \cdot 39$ & $6.21-11.09$ & $0 \cdot 48$ \\
\hline Age-adjusted rate & 698 & $1 \cdot 89$ & $1.889-1.891$ & 1353 & $6 \cdot 04$ & $6.037-6 \cdot 042$ & 0.31 \\
\hline
\end{tabular}

CI, confidence interval.

(c) 2008 The Authors

Journal Compilation (C) 2008 British Association of Dermatologists • British Journal of Dermatology 2008 158, pp766-772 

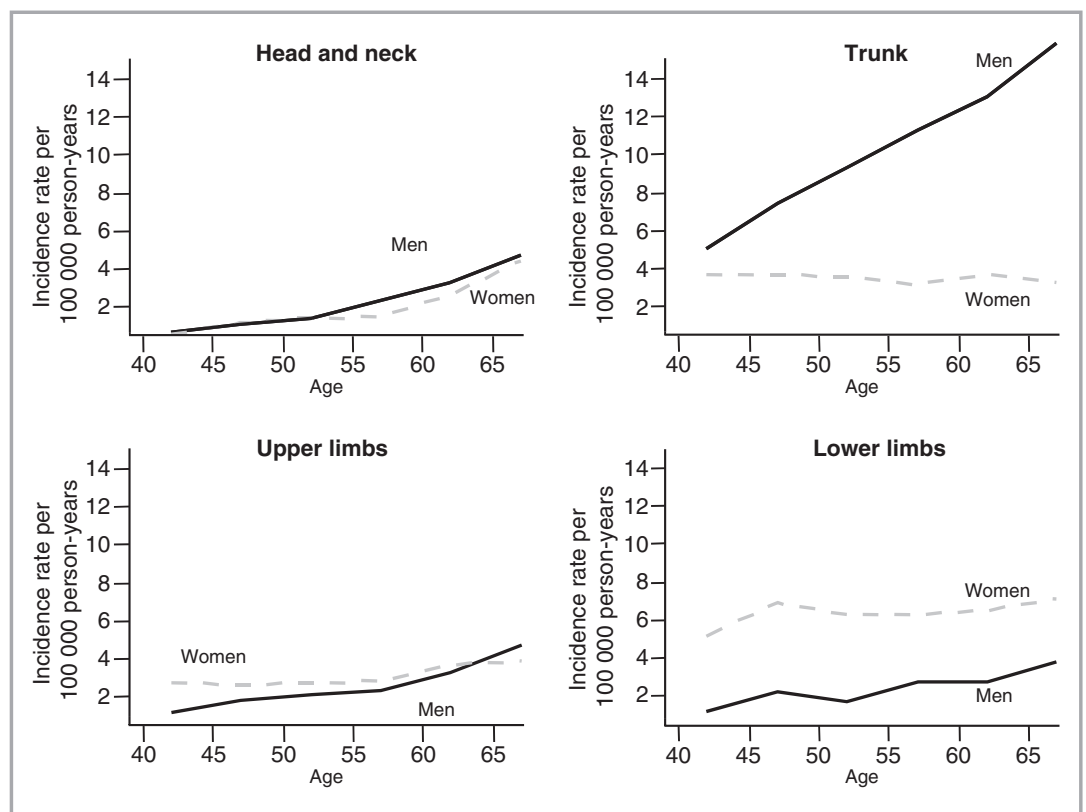

Fig 1. Cutaneous malignant melanoma incidence by site and sex in a Swedish cohort: age-specific sites adjusted for period of diagnosis, birth cohort, socioeconomic level, town size and geographical distribution. were the main causal factor, a more uniform pattern in trunk melanoma should be expected in both sexes, yet in our cohort the male/female incidence ratio for this site was $>2$.

Indeed, the relationship between sun and melanoma site has not been fully elucidated. Although Chen et al. ${ }^{34}$ observed that history of sunburn at any given body site was specifically related to the development of malignant melanoma at that same site, it is not yet clear whether the sun-CMM association is site specific or, alternatively, whether there is a susceptibility to this neoplasm at certain sites which can be triggered by any solar exposure and thereby increase melanoma risk. ${ }^{36}$ Trunk melanomas might have differential characteristics, as they are more often associated with pre-existing naevi, ${ }^{37}$ and are more strongly related than melanomas at other sites to total number of moles and other risk factors that might represent inherent susceptibility, such as family history of the disease. ${ }^{20-32,38}$

Recent research has refocused attention on the site distribution of CMM, indicating that there could be different biological pathways leading to melanoma and that their relative influence would vary by site. ${ }^{19,38}$ In this regard, some authors have suggested that susceptibility of melanocytes to malignant transformation might be site dependent, ${ }^{15}$ which could help explain why the relevance of known risk factors is not uniform by body site. ${ }^{23}$ Melanoma arising in skin without signs of chronic sun-induced damage frequently presents with BRAF mutations, ${ }^{20,39-42}$ which have been reported to be strongly associated with melanocortin-1 receptor (MC1R) variants, ${ }^{43}$ while strong p53 staining is more common in head and neck melanomas and in tumours with chronic sun-induced lesions. ${ }^{20,38,41}$ Were there to be different biological pathways to melanoma related to body site, heterogeneous biological mechanisms might conceivably underlie this different site distribution between the sexes. Rees ${ }^{44}$ stated that different body sites are preprogrammed to have differing numbers of melanocytes and constitutive melanin production, and also remarked that the amounts and type of melanin production vary with age and by site, with children being paler-skinned than adults, and women paler than men. ${ }^{21,22}$

The most remarkable difference between men and women, however, resides in the age-related change in trunk incidence, in as much as both sexes display similar rates until perimenopausal age, after which their respective trends clearly diverge. This pattern has also been described in Germany, ${ }^{25}$ Canada $^{12}$ and New Zealand, ${ }^{13}$ and some authors have suggested that these differences could be due to a cohort effect, implying that women in older cohorts might undergo less sun exposure at this site than men. Nevertheless, our estimations, derived from age-period-cohort models, enable us to rule out this possibility.

The curiously different age distribution of risk at this site by sex, which in women is reminiscent of age changes in female breast cancer rates around menopause, might support the hypothesis of a possible modulator role of sex hormones specifically in female trunk melanoma. There are several facts that render a relationship between this neoplasm and endocrine sex hormones plausible. Oestrogens are known to increase the number of melanocytes and modify their melanin content, ${ }^{45}$ and female dysplastic naevi and malignant melanocytic lesions generally seem to present more intense oestrogen receptor-beta immunostaining than those in men. ${ }^{46}$ Expression of $\mathrm{MC} 1 \mathrm{R}$ - the gene known to regulate concentration, type of melanin and shape of melanosomes in melanocytes, ${ }^{47}$ and to be related to melanoma risk ${ }^{2}$ mainly in sun-sheltered $\operatorname{areas}^{43}$ - is also modulated by specific endocrine sex hormones ${ }^{48}$ and might even have different functional effects by sex. ${ }^{49}$

At present, however, epidemiological evidence of an association between sex hormones and CMM is far from conclusive. $^{50}$ While some authors have reported a negative relationship between parity and melanoma risk, ${ }^{51}$ Kravdal $^{52}$ 
and Kaae et al. ${ }^{53}$ reported a similar association between number of children and fathers, suggesting a role for lifestyle factors rather than sex hormones. Oral contraceptives have also been suggested as a potential risk factor, although a recent meta-analysis did not support this association. ${ }^{11}$ On the other hand, overweight postmenopausal women, who are known to have a higher risk of endometrial and breast cancer after menopause, due to increased levels of circulating oestrogen, ${ }^{54}$ might also have a higher risk of CMM development. ${ }^{50}$ However, few site-specific studies have addressed reproductive and hormonal factors, those that have been conducted are too small to yield valid information, ${ }^{55,56}$ and the possible role of sex hormones in trunk melanoma therefore still remains to be studied.

In conclusion, if there are different aetiological pathways that might give rise to melanoma, a possible interaction between site and sex should be borne in mind, thereby opening avenues for new research, with the trunk being the most likely candidate for further in-depth exploration. At the present time, clear information in this area is lacking and so, in this era of molecular epidemiology, classical epidemiological variables, such as age and sex, might still be capable of furnishing essential clues and should not be overlooked.

\section{Acknowledgments}

The authors thank Michael Benedict for his help with the English, and M.J. Sánchez del Corral and P. Lozano for their assistance with the bibliographic material.

\section{References}

1 Bressac-de-Paillerets B, Avril MF, Chompret A et al. Genetic and environmental factors in cutaneous malignant melanoma. Biochimie 2002; 84:67-74.

2 Palmer JS, Duffy DL, Box NF et al. Melanocortin-1 receptor polymorphisms and risk of melanoma: is the association explained solely by pigmentation phenotype? Am J Hum Genet 2000; 66:17686.

3 Armstrong BK, Kricker A. How much melanoma is caused by sun exposure? Melanoma Res 1993; 3:395-401.

4 Eklund G, Malec E. Sunlight and incidence of cutaneous malignant melanoma. Effect of latitude and domicile in Sweden. Scand J Plast Reconstr Surg 1978; 12:231-41.

5 Pérez-Gómez B, Pollan M, Gustavsson P et al. Cutaneous melanoma: hints from occupational risks by anatomic site in Swedish men. Occup Environ Med 2004; 61:117-26.

6 Westerdahl J, Olsson H, Ingvar C et al. Southern travelling habits with special reference to tumour site in Swedish melanoma patients. Anticancer Res 1992; 12:1539-42.

7 Vagero D. Melanoma and other tumours of the skin among office, other indoor and outdoor workers in Sweden 1961-1979. Br J Cancer 1986; 53:507-12.

8 Pérez-Gómez B, Aragones N, Gustavsson P et al. Cutaneous melanoma in Swedish women: occupational risks by anatomic site. Am J Ind Med 2005; 48:270-81.

9 Westerdahl J, Olsson H, Masback A et al. Risk of malignant melanoma in relation to drug intake, alcohol, smoking and hormonal factors. Br J Cancer 1996; 73:1126-31.
10 Veierod MB, Thelle DS, Laake P. Diet and risk of cutaneous malignant melanoma: a prospective study of 50,757 Norwegian men and women. Int J Cancer 1997; 71:600-4.

11 Karagas MR, Stukel TA, Dykes J et al. A pooled analysis of 10 casecontrol studies of melanoma and oral contraceptive use. Br J Cancer 2002; 86:1085-92.

12 Elwood JM, Gallagher RP. Body site distribution of cutaneous malignant melanoma in relationship to patterns of sun exposure. Int J Cancer 1998; 78:276-80.

13 Bulliard JL. Site-specific risk of cutaneous malignant melanoma and pattern of sun exposure in New Zealand. Int J Cancer 2000; 85:627-32.

14 Armstrong BK, Kricker A. Cutaneous melanoma. Cancer Surv 1994; 20:219-40.

15 Green A. A theory of site distribution of melanomas: Queensland, Australia. Cancer Causes Control 1992; 3:513-16.

16 MacLennan R, Kelly JW, Rivers JK et al. The Eastern Australian Childhood Nevus Study: site differences in density and size of melanocytic nevi in relation to latitude and phenotype. J Am Acad Dermatol 2003; 48:367-75.

17 Kwan TY, Belke TW, Enta T. Sex differences in the anatomical distribution of melanocytic nevi in Canadian Hutterite children. J Cutan Med Surg 2000; 4:58-62.

18 Autier P, Boniol M, Severi G et al. Sex differences in numbers of nevi on body sites of young European children: implications for the etiology of cutaneous melanoma. Cancer Epidemiol Biomarkers Prev 2004; 13:2003-5.

19 Rivers JK. Is there more than one road to melanoma? Lancet 2004; 363:728-30.

20 Whiteman DC, Watt P, Purdie DM et al. Melanocytic nevi, solar keratoses, and divergent pathways to cutaneous melanoma. J Natl Cancer Inst 2003; 95:806-12.

21 Masback A, Westerdahl J, Ingvar C et al. Clinical and histopathological characteristics in relation to aetiological risk factors in cutaneous melanoma: a population-based study. Melanoma Res 1999; 9: 2-97.

22 Siskind V, Whiteman DC, Aitken JF et al. An analysis of risk factors for cutaneous melanoma by anatomical site (Australia). Cancer Causes Control 2005; 16:193-9.

23 Cho E, Rosner BA, Colditz GA. Risk factors for melanoma by body site. Cancer Epidemiol Biomarkers Prev 2005; 14:1241-4.

24 Bulliard JL, Cox B, Semenciw R. Trends by anatomic site in the incidence of cutaneous malignant melanoma in Canada, 1969-93. Cancer Causes Control 1999; 10:407-16.

25 Stang A, Stabenow R, Eisinger B et al. Site- and gender-specific time trend analyses of the incidence of skin melanomas in the former German Democratic Republic (GDR) including 19351 cases. Eur J Cancer 2003; 39:1610-18.

26 Barlow L, Eklund G. [Opening of a new database for research scientists. FoB 60 and 70 linked with the cancer registry]. Lakartidningen 1995; 92:1344, 1347.

27 Andersen A, Barlow L, Engeland A et al. Work-related cancer in the Nordic countries. Scand J Work Environ Health 1999; 25:1-116.

28 Centre for Epidemiology. Cancer Miljöregistret 1960-1970 [Cancer Environment Register 1960-1970]. EpC Rapport 4. Stockholm: Swedish National Board of Health and Welfare, 1994 [in Swedish].

29 Clayton D, Schifflers E. Models for temporal variation in cancer rates. II: Age-period-cohort models. Stat Med 1987; 6:469-81.

30 De Carli A, La Vecchia C. Age, period and cohort models: review of knowledge and implementation in GLIM. Riv Stat Appl 1987; 20:397-410.

31 Swedish Cancer Registry. Cancer Incidence in Sweden 2005. Stockholm: Center of Epidemiology, The National Board of Health and 
772 Trunk melanoma: sex-related differences in age distribution, B. Pérez-Gómez et al.

Welfare, 2007. Available at: http://www.socialstyrelsen.se/Statistik/ statistik_amne/Cancer (last accessed 5 December 2007).

32 Blair A, Zahm SH, Silverman DT. Occupational cancer among women: research status and methodologic considerations. Am J Ind Med 1999; 36:6-17.

33 Sinclair SA, Diffey BL. Sun protection provided by ladies stockings. Br J Dermatol 1997; 136:239-41.

34 Chen YT, Dubrow R, Holford TR et al. Malignant melanoma risk factors by anatomic site: a case-control study and polychotomous logistic regression analysis. Int J Cancer 1996; 67:636-43.

35 Vainio H, Bianchini B (eds). Sunscreens. IARC Handbooks of Cancer Prevention. Lyon: IARC, 2001; 1-208.

36 Weinstock MA. Controversies in the role of sunlight in the pathogenesis of cutaneous melanoma. Photochem Photobiol 1996; 63:406-10.

37 Purdue MP, From L, Armstrong BK et al. Etiologic and other factors predicting nevus-associated cutaneous malignant melanoma. Cancer Epidemiol Biomarkers Prev 2005; 14:2015-22.

38 Purdue MP, From L, Kahn HJ et al. Etiologic factors associated with p53 immunostaining in cutaneous malignant melanoma. Int J Cancer 2005; 117:486-93.

39 Curtin JA, Fridlyand J, Kageshita T et al. Distinct sets of genetic alterations in melanoma. N Engl J Med 2005; 353:2135-47.

40 Maldonado JL, Fridlyand J, Patel $\mathrm{H}$ et al. Determinants of BRAF mutations in primary melanomas. J Natl Cancer Inst 2003; 95:187890.

41 Whiteman DC, Parsons PG, Green AC. p53 expression and risk factors for cutaneous melanoma: a case-control study. Int J Cancer 1998; 77:843-8.

42 Bastian BC, Olshen AB, LeBoit PE et al. Classifying melanocytic tumors based on DNA copy number changes. Am J Pathol 2003; 163:1765-70.

43 Landi MT, Bauer J, Pfeiffer RM et al. MC1R germline variants confer risk for BRAF-mutant melanoma. Science 2006; 313:521-2.

44 Rees JL. Genetics of hair and skin color. Annu Rev Genet 2003; 37:67-90.
45 Jee SH, Lee SY, Chiu HC et al. Effects of estrogen and estrogen receptor in normal human melanocytes. Biochem Biophys Res Commun 1994; 199:1407-12.

46 Schmidt AN, Nanney LB, Boyd AS et al. Oestrogen receptor-beta expression in melanocytic lesions. Exp Dermatol 2006; 15:971-80.

47 Rouzaud F, Kadekaro AL, Abdel-Malek ZA et al. MC1R and the response of melanocytes to ultraviolet radiation. Mutat Res 2005; 571:133-52.

48 Scott MC, Suzuki I, Abdel-Malek ZA. Regulation of the human melanocortin 1 receptor expression in epidermal melanocytes by paracrine and endocrine factors and by ultraviolet radiation. Pigment Cell Res 2002; 15:433-9.

49 Mogil JS, Wilson SG, Chesler EJ et al. The melanocortin-1 receptor gene mediates female-specific mechanisms of analgesia in mice and humans. Proc Natl Acad Sci USA 2003; 100:4867-72.

50 Smith MA, Fine JA, Barnhill RL et al. Hormonal and reproductive influences and risk of melanoma in women. Int J Epidemiol 1998; 27:751-7.

51 Karagas MR, Zens MS, Stukel TA et al. Pregnancy history and incidence of melanoma in women: a pooled analysis. Cancer Causes Control 2006; 17:11-19.

52 Kravdal O. Is the relationship between childbearing and cancer incidence due to biology or lifestyle? Examples of the importance of using data on men. Int J Epidemiol 1995; 24:477-84.

53 Kaae J, Andersen A, Boyd HA et al. Reproductive history and cutaneous malignant melanoma: a comparison between women and men. Am J Epidemiol 2007; 165:1265-70.

54 Calle EE, Thun MJ. Obesity and cancer. Oncogene 2004; 23:636578.

55 Beral V, Ramcharan S, Faris R. Malignant melanoma and oral contraceptive use among women in California. Br J Cancer 1977; 36:804-9.

56 Zanetti R, Franceschi S, Rosso S et al. Cutaneous malignant melanoma in females: the role of hormonal and reproductive factors. Int J Epidemiol 1990; 19:522-6. 